\title{
Analysis of State of MV Distribution System Before and After Connection of Small Wind Farm Ravna1
}

\author{
Toni Dropulic, Mate Lasic, Jandro Simic \\ Končar Electrical Engineering Institute \\ Fallerovo setaliste 22, 10002 Zagreb (Croatia) \\ phone:+38513667 302, fax:+38513667306 \\ e-mail: toni.dropulic@koncar-institut.hr, mate.lasic@koncar-institut.hr, jandro.simic@koncar-institut.hr
}

\begin{abstract}
In the last two decades, the number of installed wind turbines has grown rapidly all over the world. This was due to the huge improvement in technology and increased interest in using wind energy as an important energy source in the future.

Following this worldwide trend, the first small wind farm in Croatia named Ravnal was installed on the Pag Island. To check its influence on local distribution network, power quality measurements have been made in different points in the network before and after the connection of the small wind farm. In parallel, simulation of the distribution network with its connection to $110 \mathrm{kV}$ network was made, and power flow and voltage analysis were made for cases of network with and without wind farm connected. Analyses were made to check the influence of the connection of the wind park on the relatively weak island network, and were made with different power outputs of wind turbines. Calculated values of power flows and values of voltages in the network match very well with measured ones. Also, measurements show that connection of small wind farm does not affect power quality on the Pag Island distribution network.
\end{abstract}

Key words: Distribution system, power quality, DFIG, wind park, EN 50160

\section{Introduction}

\section{A. MV network on the island Pag}

Southern part of the Pag Island has a distribution $10 \mathrm{kV}$ network powered from Pag 110/10 kV substation with two $110 \mathrm{kV}$ overhead lines connecting this island with the mainland. Pag substation has one power transformer (10 MVA $110 / 10 \mathrm{kV}$ ), which is enough to supply radial network that mostly consists of underground cables with forty distribution substations $(10 / 0,4 \mathrm{kV})$.

Overhead $10 \mathrm{kV}$ lines are rare with total length of $2 \mathrm{~km}$, which is a minor length comparing to $81 \mathrm{~km}$ of total length of underground cables, and it is local utility's intention to replace them with underground cables.

MV network layout in major overview is given in Fig. 1, with small wind farm Ravnal included.
The point of common coupling for the small wind park Ravnal is node Kirsina, which is also one of $10 / 0,4 \mathrm{kV}$ distribution substations.

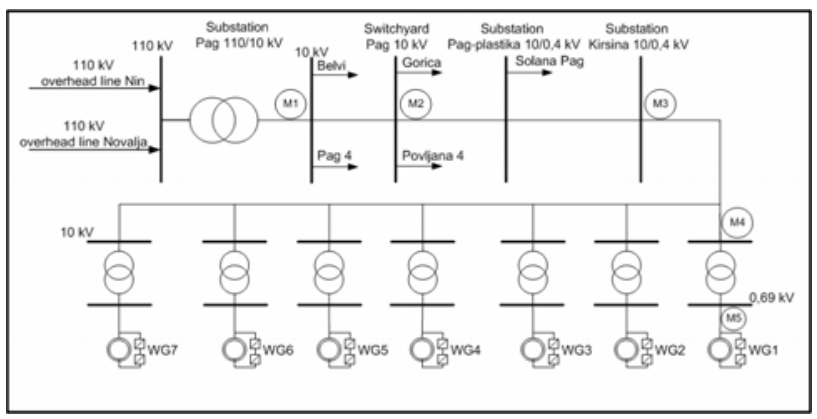

Fig. 1. Connection of the small wind farm Ravnal to the distribution network of the Pag Island

\section{B. Small wind farm Ravnal}

Small wind farm Ravna1 consists of 7 Vestas V52$850 \mathrm{~kW}$ wind turbines, which means total installed power of 5.95 MW. These are wind turbines with variable rotor speed and doubly-fed induction generator (DFIG). All data about these wind turbines were obtained from [1], and [2]. The connection of the small wind farm Ravnal is shown in Fig. 1. Wind generators are marked with WG1 $\div$ WG7.

General principles of operation of DFIG generators were found in [3]. Main problems wind turbines may cause in the network are fluctuations of voltage and power production caused by wind fluctuations. This change of voltage causes generation of flicker. The higher the shortcircuit power at the point of common coupling, the lower the flicker emission value.

Also, as this wind turbine type has a power converter in the rotor circuit, they inject a certain amount of harmonic currents into the network they are connected to, hence causing distortion of voltage at the point of coupling. Switching wind generators causes inevitable transients. 


\section{Power quality measurements before connection of the small wind farm}

Power quality measurements have been carried out from 09.07.2004 till 16.07.2004 and from 16.07.2004 till 23.07.2004 at two locations on the island of Pag, according to [4].

Consumers are mostly households and tourist objects and as these measurements were done during tourist season they represent maximum load. As measurements were made during very hot and sunny weather, large influence from non-linear consumers is expected (air-conditioners). Measurement points are shown in Fig. 1.

First location is $10 \mathrm{kV}$ side of power transformer in substation 110/10 kV Pag (M1) which represents complete consumption of this substation and $10 \mathrm{kV}$ network. Daily load diagrams do not differ significantly in the whole measurement period of seven days. Peak loads of 4.5 MW were measured. Voltage distortion was $1-2 \%$, and current distortion 2-6\%. Electric energy quality in this measurement point fulfils all criteria as in [4]. Graphic representations of measurement results in substation Pag 110/10 kV according to [4] are shown in Fig. 2.

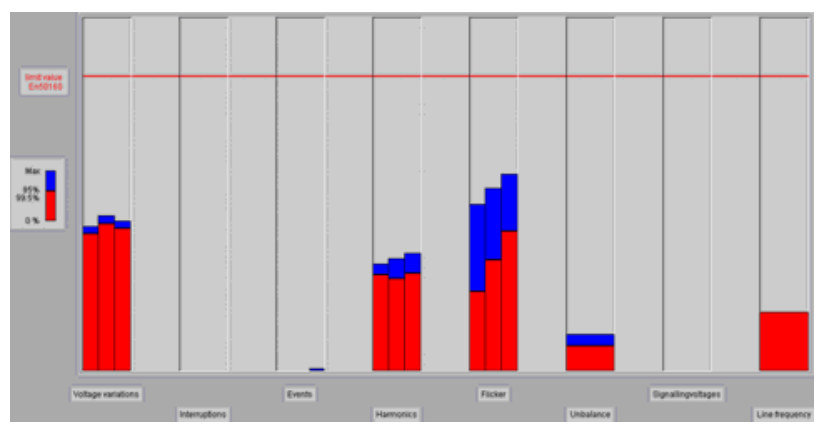

Fig. 2. Graphic representation of power quality measurement results according to [4] in substation Pag 110/10 kV

Second measurement location is in switchyard Pag $10 \mathrm{kV}$ on line to substation Pag-plastika (M2). In substation Pag-plastika there is a line to substation Kirsina, which is the point of common coupling of small wind farm Ravna1. Daily load diagrams do not differ significantly during working days. Peak loads measured reached $800 \mathrm{~kW}$. Quality of electrical energy in this measurement point also fulfils all terms according to [4]. Graphic representations of measurement results in switchyard Pag according to [4] are shown in Fig. 3. It is important to notice very high flicker levels during power quality monitoring, but in less than $5 \%$ of measurement time.

In Fig. 4 a) are shown time diagrams of short-term $\mathrm{P}_{\text {st }}$ and long-term flickers $\mathrm{P}_{\mathrm{lt}}$ in $\mathrm{L} 1$ phase.

In Fig. 4 b) are shown time diagrams of minimum and maximum values of voltage $(10 \mathrm{~ms}$ values $)$, and also values of current in moments of minimum and maximum values of voltage in phase L1. As named figures represent, cause of high flicker values are overvoltages and voltage drops. Loads do not cause these voltage changes.

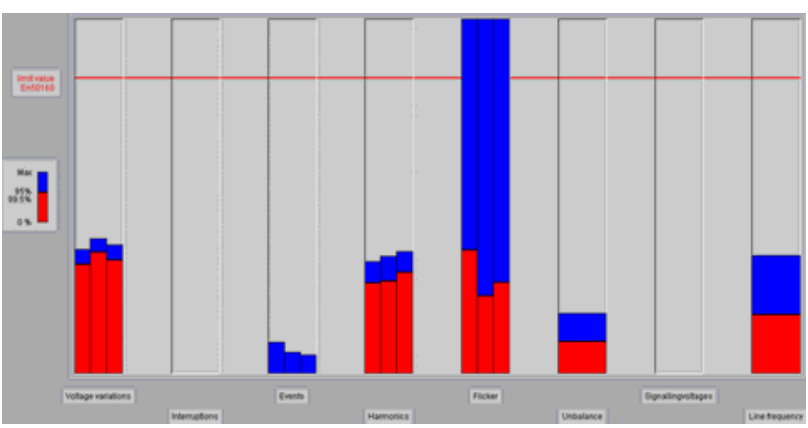

Fig. 3. Graphic representation of power quality measurement results according to [4] in switchyard Pag $10 \mathrm{kV}$

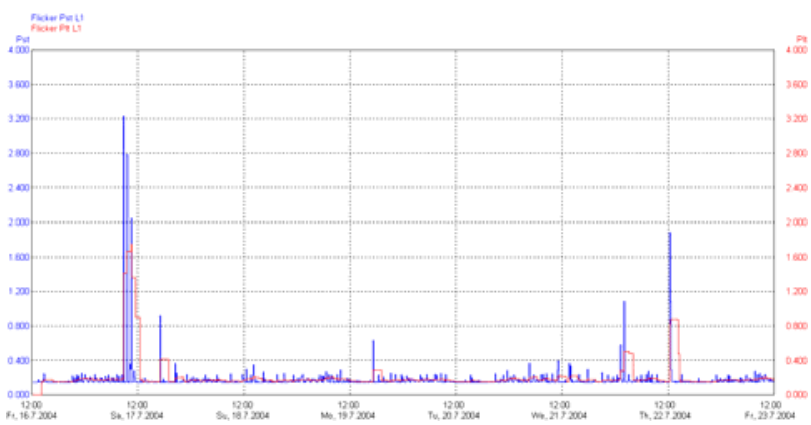

a)

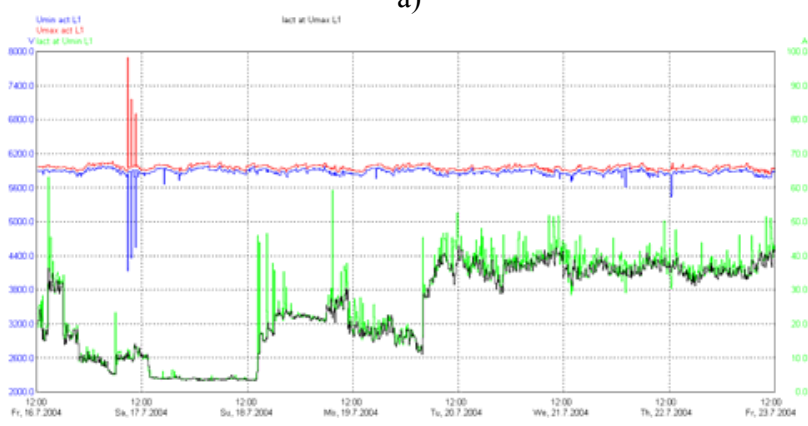

b)

Fig. 4. a), b) Analyses of flicker measurement results in switchyard Pag $10 \mathrm{kV}$

\section{Power quality measurements after connection of the small wind farm}

Power quality measurements after connection of the small wind farm Ravna1 were taken from 24.02.2005 till 03.03.2005 at two points at the same time (M1 $-10 \mathrm{kV}$ side of power transformer in substation Pag $110 / 10 \mathrm{kV}$ and M3 - at the point of common coupling in Kirsina substation). Measurements were made with two Memobox 808 instruments.

Graphic representations of voltage quality measurement results in substation Pag 110/10 kV (M1) are shown in Fig. 5, and graphic representations of voltage quality measurement results at the point of common coupling (M3) are shown in Fig. 6, both measurements according to [4]. 
Comparing these measurements we can make next conclusions:

a. Voltage oscillations are more expressed at the point of common coupling (M3),

b. At both measurement points high flicker levels are registered in less than $5 \%$ of total measurement time

c. Voltage frequency values, asymmetry of voltage and voltage harmonics are approximately same at both measurement points, as well as number of occurrences (overvoltages and voltage drops)

However, quality of voltage at both of these measurement points completely fulfils all requests as given in [4]. Voltage fluctuations are quite expressed at the point of common coupling (M3) as an inevitable consequence of operation of the small wind farm.

Phase voltage at the point of common coupling is higher than phase voltage at Pag substation during periods of wind farm Ravnal producing more power $\left(0.5 * \mathrm{P}_{\mathrm{n}}\right.$ and higher), as shown in Fig. 6.

Production of the small wind farm Ravnal sometimes occurs to be higher than total power consumed by all loads in the $10 \mathrm{kV}$ distribution network.

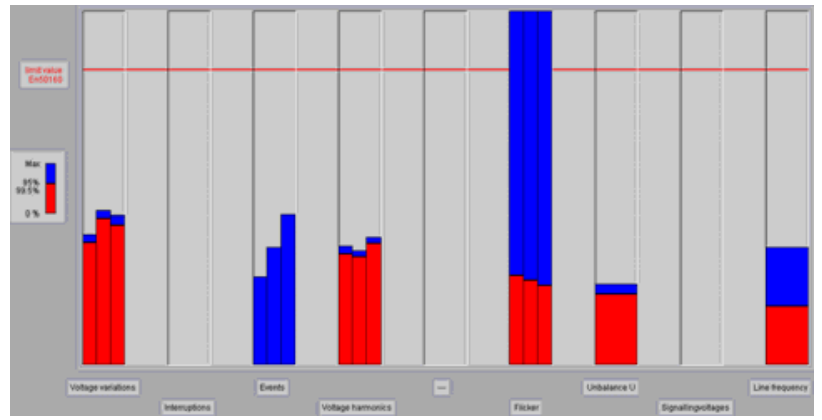

Fig. 5. Graphic representations of voltage quality measurement results according to [4] at Pag substation 110/10 kV (M1)

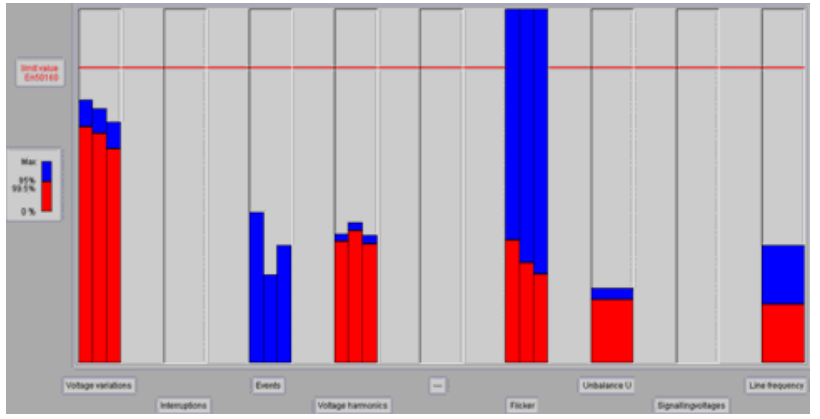

Fig. 6. Graphic representations of voltage quality measurement results according to [4] at the point of common coupling (M3)

During relatively high power production of the small wind farm Ravnal $\left(\mathrm{P}=0.5^{*} \mathrm{P}_{\mathrm{n}}\right.$ and higher), voltage total harmonic distortion (THD) level is lower in the whole distribution network. Voltage THD at the point of common coupling (M3) at these power production levels is lower than in substation Pag $110 / 10 \mathrm{kV}$ (M1), which is represented in Fig. 8. $5^{\text {th }}$ voltage harmonic is the most expressed.

All voltage values and THD levels in the network are under limits set in [4].

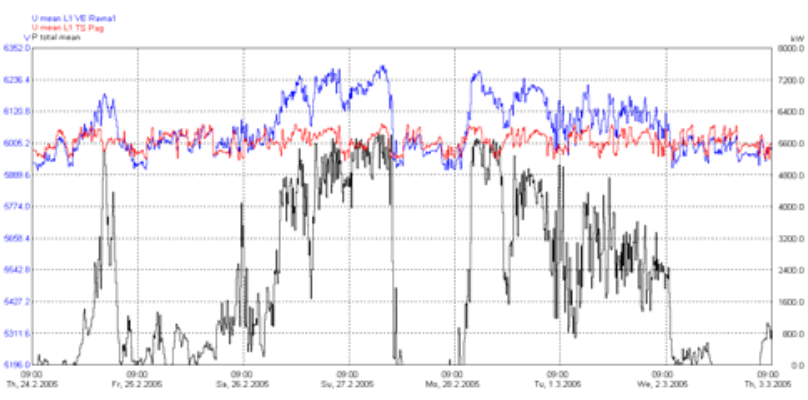

Fig. 7. Comparison of voltages at $10 \mathrm{kV}$ side at Pag substation and at the point of common coupling

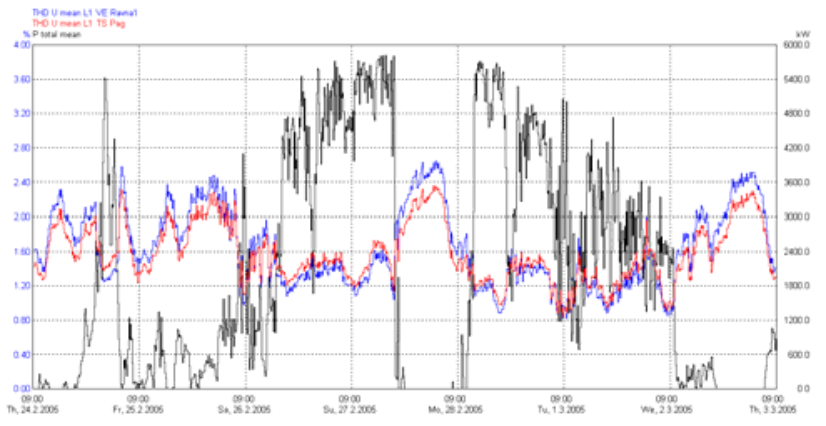

Fig. 8. Voltage distortion at $10 \mathrm{kV}$ side at Pag substation and at the point of common coupling

Fig. 9 gives comparison of 10-minute average values of $5^{\text {th }}$ harmonic of current and voltage (in percent of nominal values of current and voltage), and $5^{\text {th }}$ harmonic of total current at the point of common coupling of small wind farm Ravna1 (M3), all in phase L1.

During high production level of small wind farm $\left(50 \% * \mathrm{P}_{\mathrm{n}}\right.$ and higher), level of $5^{\text {th }}$ harmonic of voltage is getting lower in despite of raise of $5^{\text {th }}$ harmonic of current, as percent values of $5^{\text {th }}$ harmonic of both current and voltage are approximately the same.

Highest levels of $5^{\text {th }}$ harmonic are during periods when wind farm is disconnected. Considering these results, we can see that at relatively high production power of small wind farm $\left(50 \% * \mathrm{P}_{\mathrm{n}}\right.$ and higher) change in power flows of $5^{\text {th }}$ harmonic occurs.

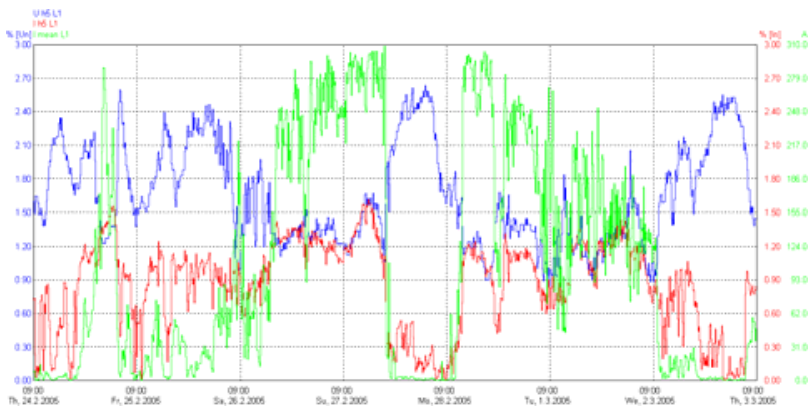

Fig. 9. Comparison of $5^{\text {th }}$ harmonic of current, voltage and total current at the point of common coupling (M3)

In Fig. 10 a) are shown time diagrams of short-term flicker $\mathrm{P}_{\mathrm{st}}$ and long-term flicker $\mathrm{P}_{\mathrm{lt}}$ in phase $\mathrm{L} 1$ at the point of common coupling (M3).

In Fig. 10 b) are shown time diagrams of minimum and maximum values of voltage $(10 \mathrm{~ms}$ values $)$, and also values of current in moments of minimum and maximum values of voltage in phase L1. 


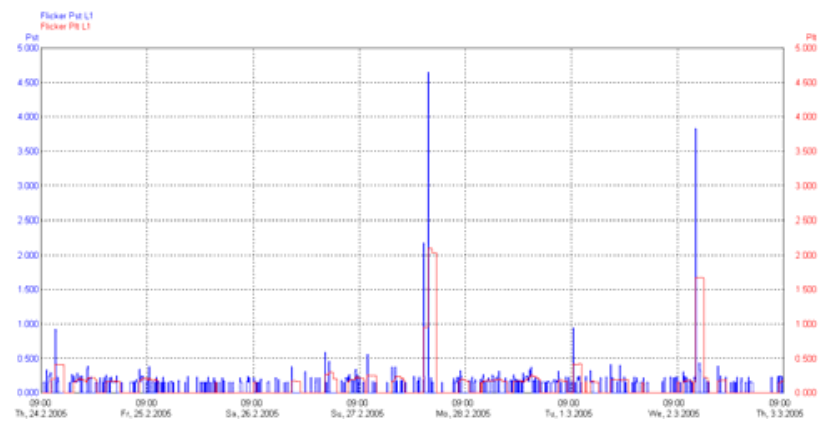

a)

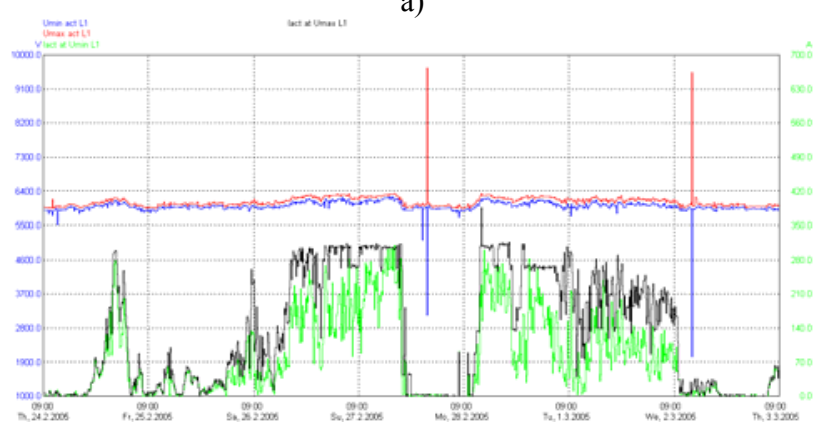

b)

Fig. 10. a), b) Analyses of flicker measurement results at point of common coupling (M3)

As named figures represent, cause of high flicker values are overvoltages and voltage drops. These voltage changes are not caused by operation of small wind farm Ravna1.

Power factor measurement results at the point of common coupling (M3) in correlation with nominal active power of small wind farm Ravnal (5,95 MW) are shown in Fig. 11. It is noticeable that power factor already at $20 \% * P_{n}$ reaches value of approximately 1 . At very low values of output active power factor is negative, i.e. wind farm is consuming inductive reactive power from the distribution network.

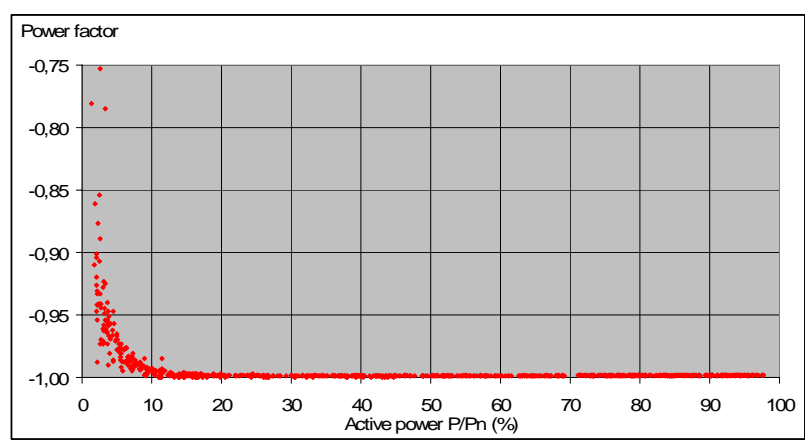

Fig. 11. Results of power factor measurement at the point of common coupling (M3)

Results of measurement of total harmonic distortion of current in correlation with nominal active power at the point of common coupling (M3) are shown in Fig. 12. Total harmonic distortion factor of current is already at values of active power of $20 \% * \mathrm{P}_{\mathrm{n}}$ less than $10 \%$. At very low values of output active power of small wind farm distortion of current reaches very significant values.

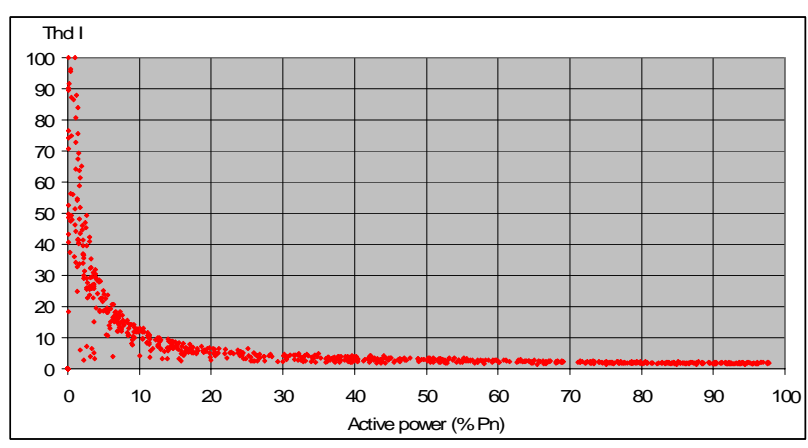

Fig. 12. Results of measurement of total harmonic distortion of current at the point of common coupling (M3)

\section{Network analysis and power flow calculations before and after connection of the small wind farm}

Results of measurements taken before connection of the small wind farm were used in the static power flow and voltage profile calculation.

Measured values of power flows in measurement points were used to make equivalent loads in the network model where possible. For those points, measurement results were directly used as loads in those points. For all other points, loads were estimated to $30 \%$ of apparent power of transformer installed in that point, with active/reactive power ratio set to $3 / 1$, which means power factor of 0,95 .

With network set in this way, sum of active power in all substations in the network reaches $4 \mathrm{MW}$, with apparent power of 4,2 MVA, and the power flowing through Pag $110 / 10 \mathrm{kV}$ substation should be near this value in case without wind farm connected.

Wind generators were modeled as PQ nodes, with fixed amount of active and reactive power they exchange with the network.

Cables and transformers were simulated with П-models, and it is important to notice that cable characteristics have large impact on the calculation results due to their large capacitance, which causes them producing a lot of inductive power.

Calculations were made for three cases:

- Wind farm disconnected from the network (e.g. state of network before connection of the small wind farm Ravna1),

- Each wind generator producing nominal active power of $850 \mathrm{~kW}$, while consuming nominal $4 \mathrm{kVAR}$ of reactive power $(\cos \varphi \approx 1)$,

- Each wind generator producing half of its nominal active power $(425 \mathrm{~kW})$, while consuming $4 \mathrm{kVAR}$ of reactive power.

When observing power flows in the network, it is necessary to compare power flows for the three mentioned power flow calculation cases, as it is shown in Fig. 13. 


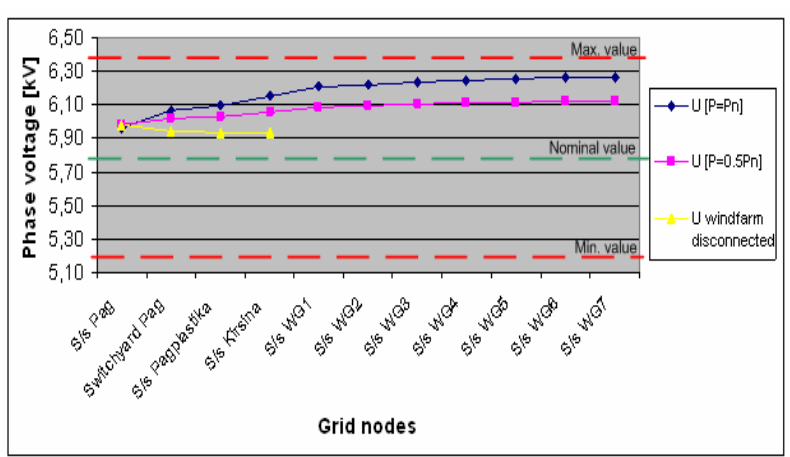

Fig. 13. Voltage profiles across the network for different power productions levels of small wind farm Ravnal

In case of wind farm disconnected from the network, the whole distribution network is powered from $110 \mathrm{kV}$ side of Pag substation, and in that case active power flowing through $110 / 10 \mathrm{kV}$ transformer is $4,59 \mathrm{MW}$, with 1,39 MVAR of inductive power consumed on the $10 \mathrm{kV}$ side. This energy is distributed to equivalent loads, which are not shown in Fig. 14, and is partly dissipated on distribution cables.

Case when each of wind generators produces nominal active power brings out active power injected into the network at the point of common coupling equal to 5,91 MW, while taking 0,28 MVAR of inductive power from the network, what makes total power factor at the point of common coupling $\cos \varphi \approx 1$.
When each wind generator is producing active power of $425 \mathrm{~kW}$, active power injected into the network at point of common coupling is $2,97 \mathrm{MW}$, what together with 0,07 MVAR of consumed inductive power also makes $\cos \varphi \approx 1$.

Voltage profile results for characteristic nodes in the network given as a comparison of these three cases are shown in Fig. 13 (SWG1 $\div$ SWG7 are $10 \mathrm{kV}$ sides of wind generator substations). In each of these cases line-to-line voltage on the $110 \mathrm{kV}$ bus of Pag $110 / 10 \mathrm{kV}$ substation was fixed to $110+\mathrm{j} 0 \mathrm{kV}$. Calculations were made with all loads in the network included.

Noticeably, wind farm causes rising of phase voltage values in the network, but they remain between borders of $-10 \%$ and $+10 \%(5196 \mathrm{~V}-6352 \mathrm{~V})$ around nominal value $(5770 \mathrm{~V})$, which is the limit allowed in $\mathrm{MV}$ networks [4], so it does not cause any problems in the network. It is necessary to notice that voltage values in the whole network were higher than nominal even before connection of the small wind farm Ravna 1.

Conclusion of these static power flow calculations is that operation of wind farm Ravnal makes large influence on the distribution network power flow and voltage values, but none of the network elements is overloaded and voltages in all nodes in the network are as set in [4].

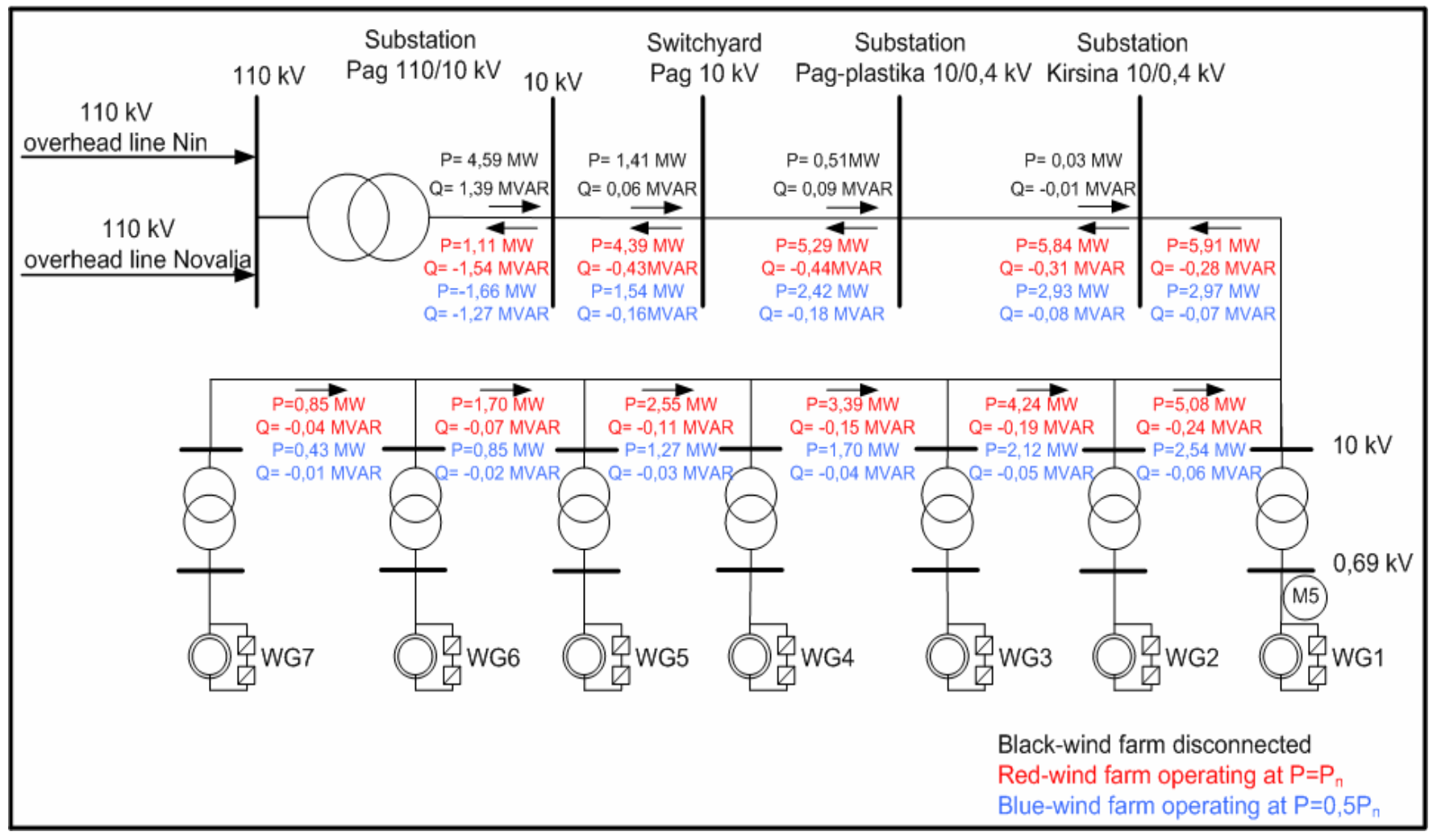

Fig. 14. Power flows in the distribution network for three power production levels of wind farm Ravnal 


\section{Comparison of measured and calculated values}

A comparison of measured and calculated voltage and power flow values is made comparing Fig. 9 with Fig. 13 and Fig. 14. Comparison of voltages at the point of common coupling and at $\mathrm{S} / \mathrm{s}$ Pag for different levels of power production of small wind farm Ravna 1 is given in Table I.

Table I. - Comparison of measured and calculated values

\begin{tabular}{|c|c|c|c|}
\hline $\begin{array}{c}\text { Wind farm } \\
\text { production level }\end{array}$ & Grid nodes & $\begin{array}{c}\text { Phase } \\
\text { voltage, } \\
\text { measured } \\
\text { values [V] }\end{array}$ & $\begin{array}{c}\text { Phase } \\
\text { voltage, } \\
\text { calculated } \\
\text { values [V] }\end{array}$ \\
\hline $\begin{array}{c}\mathrm{P}=\mathrm{P}_{\mathrm{n}} \\
\mathrm{P}_{\text {inj }}=5,91 \mathrm{MW}\end{array}$ & S/s Kirsina & 6280 & 6150 \\
\cline { 2 - 4 } & $\mathrm{S} / \mathrm{s}$ Pag & 6020 & 5960 \\
\hline $\begin{array}{c}\mathrm{P}=0,5 \mathrm{P}_{\mathrm{n}} \\
\mathrm{P}_{\text {inj }}=2,97 \mathrm{MW}\end{array}$ & S/s Kirsina & 6070 & 6060 \\
\cline { 2 - 4 } $\begin{array}{c}\text { Wind farm } \\
\text { disconnected }\end{array}$ & S/s Pag & 6010 & 5981 \\
\cline { 2 - 4 } & S/s Kirsina & 5970 & 5937 \\
\hline \multicolumn{2}{|c|}{} & 6000 & 5980 \\
\hline
\end{tabular}

$P_{\text {inj }}$ in Table I is power injected into the network at the point of common coupling, and voltages were taken for those values of power at the substation Pag (M1) and at the point of common coupling (M3). The results match quite well, with one remark: at power production level of $\mathrm{P}=\mathrm{P}_{\mathrm{n}}$ of all wind turbines, maximal measured power injected into the network at the point of common coupling was $5,8 \mathrm{MW}$, so it is one of the causes why the results of voltage for this case differ from calculated values. The main case of difference in results are, of course, imperfection of the simulation model, and not knowing real state of all loads in the network, as not all of them are consuming power all the time, as it was the case in our simulation. This is why measured values of voltage are higher than calculated in all cases.

\section{Conclusion}

Power quality measurements and load flow calculations presented in this work show that connection of small wind farm Ravnal mainly affects voltage levels and voltage distortion in the network, especially at the point of common coupling.

Higher voltage level at the point of common coupling is a natural consequence of injecting power into the network.

Lowering of voltage distortion levels during operation of small wind farm is explained by higher short-circuit power at the point of common coupling and in change of load flows of all harmonics in the network.

All measurements and analysis have confirmed that operation of the small wind farm Ravnal on the Pag Island does not disturb power quality in the distribution network of the Pag Island.

\section{References}

[1] General specification V52-850 kW with OptiSpeed - wind turbine, Vestas, Denmark, 2001

[2] Test report-Power quality measurements at the wind turbine Vestas V52-850 kW, NR 01 0506.1, German Wind Energy Institute, Fogderup, Denmark, 2002

[3] Torbjorn Thiringer and Andreas Petersson, "Grid Integration of Wind Turbines", Swedish-Polish Motion Control and Wind Energy Symposium, Warszawa, Poland, October 22, 2003

[4] EN 50160: 1999, Voltage characteristics of electricity supplied by public distribution systems.

[5] IEC 61400-21: Wind turbine generator system; Part 21: Measurement and assessment of power quality characteristic of network-connected wind turbines. 